Letters to the Editor

\section{Early Prevention and Screening of Cervical Cancer in a Developing Country}

We have read with much interest an article recently published by Ekwueme et al. ${ }^{1}$ about the impact of the National Breast and Cervical Cancer Early Detection Program on cervical cancer mortality among uninsured low-income women in the U.S. Cervical cancer is a relevant issue in Peru, owing to its high incidence and mortality rate when compared with other countries. ${ }^{2}$ Despite being a fully preventable cancer with a clearly known pathogen, its early prevention and detection remains a problem in Peru, which is worsened by poverty conditions and inadequate access to health care, as well as unequal distribution of health workers among the country's different regions. ${ }^{3}$

Cervical cancer has the second highest incidence and mortality rates of all cancers among women of all ages in Latin America. ${ }^{4}$ Peru has a population of 10.87 million women aged $\geq 15$ years who are at risk of developing cervical cancer. ${ }^{5}$ An epidemiologic cancer surveillance program reported 109,914 cases in the 2006-2011 period, during which cervical cancer was the most common cancer among women $(24.1 \%){ }^{6}$ Of all the reported cases of cervical cancer, only $5.6 \%$ were diagnosed through an early detection program, a troubling finding that showcases the need for better screening coverage.

Although the percentage of cervical cancer cases diagnosed through early detection has shown an incremental increase in recent years, from 3.7\% in 2006 to $6.8 \%$ in 2011 , the number remains unsatisfactory, and it is clear that there is a long road ahead until satisfactory cervical cancer prevention results such as those reported by Ekwueme et al. are achieved in Peru. ${ }^{6}$ Differences in the healthcare systems could be one explanation as to why screening methods have not yet shown results as promising as those in other countries. The authors recommend that more studies be conducted regarding prevention of cervical cancer in developing countries so that strategies may be undertaken to improve screening coverage and reduce its incidence and mortality.

\section{Alvaro Carvallo-Michelena Jorge Luis Rojas-Dominguez Alejandro Piscoya}

Escuela de Medicina Universidad Peruana de Ciencias Aplicadas

Lima, Peru

http://dx.doi.org/10.1016/j.amepre.2014.11.001
No financial disclosures were reported by the authors of this paper.

\section{References}

1. Ekweme DU, Uzunangelov VJ, Hoerger TJ, et al. Impact of the National Breast and Cervical Cancer Early Detection Program on cervical cancer mortality among uninsured low-income women in the U.S., 1991-2007. Am J Prev Med. 2014;47(3):300-308. http://dx.doi.org/10.1016/ j.amepre.2014.05.016.

2. Levinson K, Abuelo C, Chyung E, et al. The Peru Cervical Cancer Study (PERCAPS): community based participatory research in Manchay, Peru. Int J Gynecol Cancer. 2013;23(1):141-147. http://dx.doi.org/ 10.1097/IGC.0b013e318275b007.

3. Global Health Workforce Alliance. Progress report on the Kampala Declaration and Agenda for Global Action. Peru: WHO 2014. www.who. int/workforcealliance/countries/per/en/.

4. Pan American Health Organization. Cervical Cancer Prevention and Control Programs: A Rapid Assessment in 12 Countries of Latin America. Washington, DC: PAHO; 2010.

5. Bruni L, Barrionuevo-Rosas L, Serrano B, et al. ICO Information Centre on HPV and Cancer (HPV Information Centre). Papillomavirus and related diseases in Peru. Summary Report. 2014-08-22.

6. Ramos WC, Venegas DR. Análisis de la Situación del Cáncer en el Perú, 2013. Ministerio de Salud: Dirección General de Epidemiología. 2013; $1(1)$

\section{Early Prevention and Screening of Cervical Cancer in a Developing Country-Reply}

Drs. Carvallo-Michelena and Rojas-Dominguez describe the importance of documenting the impact of cervical cancer screening programs and the relevance of impact measurement to low- and middle-income countries (LMICs) like Peru.

We agree with the authors regarding the need to evaluate the impact of health prevention efforts such as cervical cancer screening in Peru. The evaluation effort is necessary to quantify impact, provide accountability, and show return on investment to the ministry of health or donors funding the intervention. Further, it provides invaluable information to decision makers on progress toward the prevention of cervical cancer. Through its ProVac Initiative, the Pan American Health Organization (PAHO) has been strengthening country capacity to collect relevant data and develop economic tools for both human papillomavirus (HPV) vaccination and cervical cancer screening. ${ }^{1}$

Low- and middle-income countries can use modified methods to evaluate the impact of pilot screening 